\title{
Borrowed identities: Class(ification), inequality and the role of credit- debt in class making and struggle
}

\author{
Matthew Sparkes \\ Department of Sociology, University of Cambridge, UK
}

\begin{abstract}
Class analysis has re-emerged as a pertinent area of enquiry. This development is linked to a growing body of work dubbed cultural class analysis, that utilises Bourdieu's class scheme to develop rich understandings of how culture and lifestyle interacts with economic and social relations in Britain, generating inequalities and hierarchies. Yet cultural class analyses do not properly account for the way individuals resist their relative class positions, nor the role of unsecured credit in facilitating consumption. This article contributes to this area by examining how unsecured credit and problem debt influences consumption and class position amongst individuals with modest incomes. Drawing on 21 interviews with individuals managing problem debt, this article details how class inequality emerges through affective states that include anxiety and feelings of deficit. It also shows how these experiences motivate participants to rely on unsecured credit to consume cultural goods and engage in activities in a struggle against their class position, with the intention of enhancing how they are perceived and classified by others. The findings indicate that cultural class analyses may have overlooked the symbolic importance of mundane consumption and goods in social differentiation. This article further details how these processes entangle individuals into complex liens of debt which lead to over-indebtedness, default, dispossession and financial expropriation - illustrating how investigations of credit-debt can better inform understandings of class inequality, exploitation and struggle.
\end{abstract}

\section{Keywords}

capital, consumption, credit and problem debt, cultural class analysis, exploitation, inequality

\section{Introduction}

Credit is about living a lifestyle that you think you should be having... but that you haven't got.

(Anne, 50, business mentor)

Class analysis has re-emerged as a pertinent area of inquiry. This development is linked to a growing body of work dubbed 'cultural class analysis' (Holt, 1998; Savage, Warde \& Devine, 2005; 
Bennett et al., 2009; Savage et al., 2013, 2015; Friedman, Savage, Hanquinet, \& Miles, 2015), that utilises Bourdieu (1984; 1986)'s class scheme to develop rich understandings of how culture, lifestyle and taste interacts with economic and social relations in Britain, generating inequalities and hierarchies (Silva, 2015). Yet cultural class analyses do not properly account for how individuals resist their relative class positions (Tyler, 2013, 2015; Shildrick \& MacDonald, 2013), nor the role of financial resources in facilitating consumption (Crompton, 2010; Skeggs, 2015). This paper contributes to this area by drawing on the findings of a qualitative study that examined the role of personal credit and problem debt in processes of class making and struggle.

Personal credit is ubiquitous in contemporary Britain. Levels outstanding have accelerated since 2014: reaching $£ 1.592$ bn by 2018 , more than the total owed during the 2007-8 financial crisis (see Figure 1). Approximately $51 \%$ of British households have some credit-debt (Harari, 2018, p. 17), either secured or unsecured. Secured debt is a loan secured on an asset, which can subsequently be used as collateral in the case of default. Secured lending through mortgages account for the majority of household debt (see Figure 1). Unsecured debt is lending that is not secured on an asset, and includes credit cards, overdrafts, personal and payday loans. Moreover, 8\% are in problem debt (Harari, 2018, p. 20), whereby households have defaulted on their credit agreement(s) and cannot meet repayment(s).

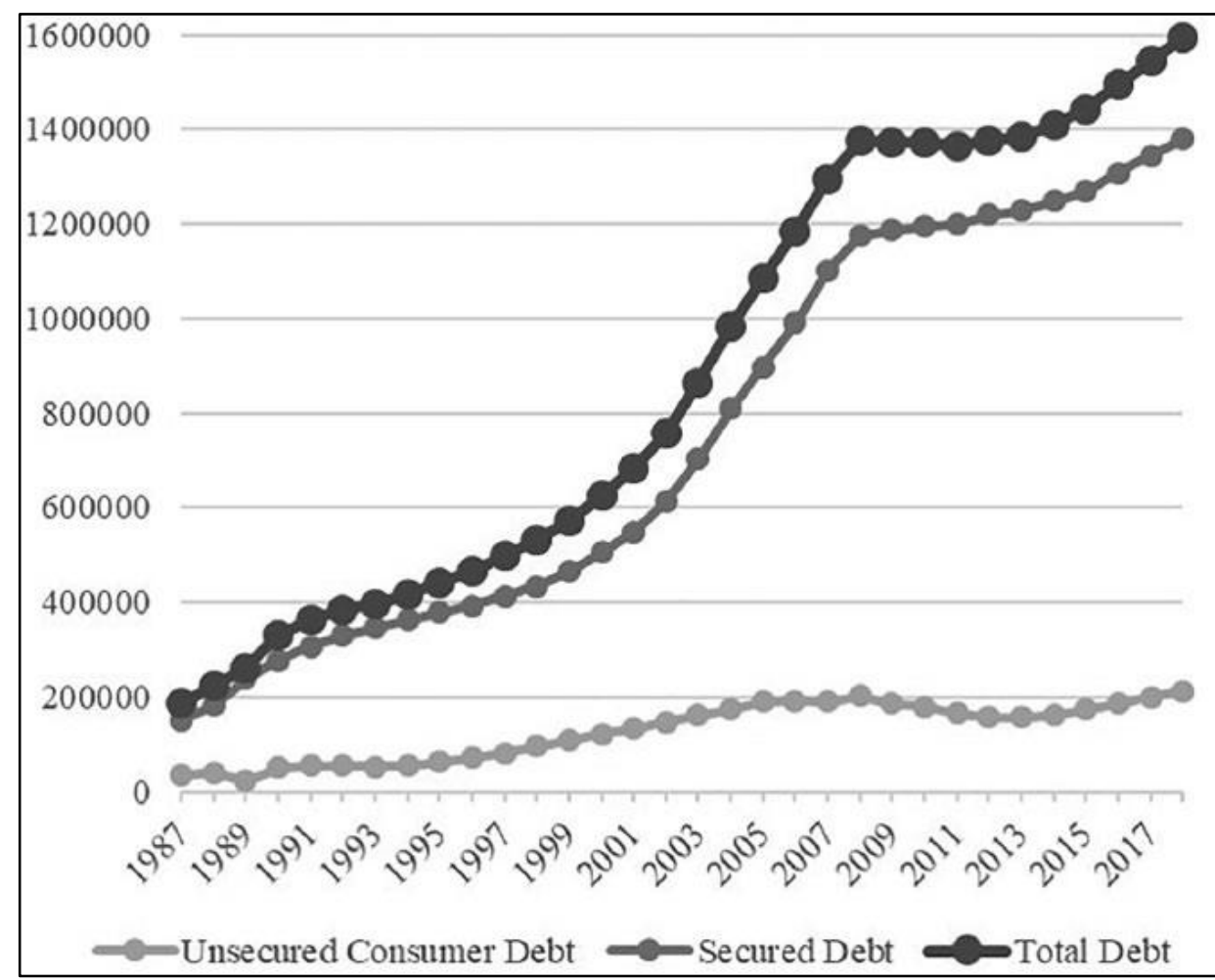

Figure 1. Amounts outstanding of net lending (in sterling millions) to individuals, 1987-2018.

Source: Bank of England (2018).

Note: Excludes student loans. 
Lazzarato (2012) argues that indebtedness is a common, defining feature of life under neoliberal capitalism: characterised by strong property rights, free markets, and the increasing dominance of the financial sector (Duménil \& Lévy, 2001; Harvey, 2007; Payne, 2013). Lazzarato (2012, p. 162) further contends that debt surpasses divisions in the productive sphere, divisions on which class analysis throughout the twentieth century 'based its categories of thought and action', particularly through investigations of exploitative labour relations and/or occupational level mobility (Goldthorpe, 1987). Scholars have investigated how individuals are integrated into financial markets through stocks, investments and pensions (Langley, 2008); expansion of mortgage debt to widen access to private home ownership (Wood, 2017); and the use of unsecured consumer credit in response to amplifying inequality. This paper is concerned with the latter, given that unsecured credit is used exclusively to fund consumption (Montgomerie, 2009).

The dominant view is that this relationship moves from distribution to debt, as lower income households take on unsecured debt to meet essential consumption, which has become increasingly necessary given the 'austerity' measures adopted in Britain since 2010 (Froud, Sukhdev, Montgomerie, \& Williams, 2010; Walker, 2011; Montgomerie, 2016). Whilst there is some evidence supporting this, the proportion of British households with unsecured debt is higher in middle-toupper-middle income groups, who also have larger unsecured debts as a proportion of household income (Harari, 2017, p. 20; see Montgomerie, 2009, for similar findings in the US). Marxist political economy (Duménil \& Levy, 2001; Harvey, 2004; Lapavitsas, 2009; Soederberg, 2013; Toscano \& Woodcock, 2015) holds that the rise of household indebtedness has occurred in advanced financialised economies because they are structured in a way that normalises secondary forms of exploitation: which Harvey (2004) dubs 'accumulation by dispossession'. However, this insufficiently accounts for the important role of individual agency (Wood, 2017) in driving credit use.

Alternatively, Frank, Levine, and Dijk (2010), Bertrand and Morse (2011), and van Treeck (2012) contend that visibly increased consumption by high income individuals has induced statusseeking consumption by middle income individuals; and in turn, their lower income counterparts, leading to rising indebtedness. This takes us far from the orthodox economic view of consumer credit: that it exists to smoothen consumption across the lifecycle (Ando \& Modigliani, 1963; see Sparkes, Gumy, \& Burchell, 2018, for a critique). However, such conclusions are limited by their narrow focus on economic inequality and reliance on quantitative methods, which cannot account for how inequality operates through forms of valuation and affect (Bottero, 2004; Savage et al., 2013; Skeggs, 2015; Tyler, 2015). Additionally, this research has been conducted in the US; it is unclear how these findings translate to a British context, especially in the entanglement of inequality, credit and consumption among those with modest incomes. 
This paper contributes to these debates by exploring inequality, not as a macro-structural variable, but a domain of experience - a particular system of effects, emotions, and intensities. I champion a relational mode of analysis that draws inspiration from Bourdieusian-inspired cultural class analysis; but expand on this framework by addressing how unsecured credit influences consumption and class position (Sullivan, 2008). Drawing on interviews with 21 individuals managing problem debt, I detail how class inequality emerges through affective states that include anxiety and feelings of deficit (Savage et al., 2013, 2015). I also show how these experiences motivate participants to rely on unsecured credit to consume, often mundane, cultural goods in a struggle against their class position, with the intention of enhancing how they are perceived and classified by others. The findings indicate that cultural class analyses may have somewhat overlooked the symbolic importance of mundane consumption and goods in social differentiation. The participants would not fall into popular narratives of 'poverty'; their incomes are enough to meet monthly outgoings such as mortgages/rent, utilities and transport, pay for food and modest entertainment. This paper therefore explores separate modalities of debt and provides significant insights into the high proportion of unsecured debt held by those outside lower income groups. In addition, I detail how participants' accumulation of credit to fund consumption has left them servicing large stocks of unsecured debt: further entangling them in liens of debt, resulting in financial expropriation (Lapavitsas, 2009) and dispossession (Harvey, 2004). I further argue the ways in which class inequality induce credit-driven consumption are critical in understanding the landscape of class exploitation in contemporary Britain.

The paper proceeds as follows. The first section explores emergent paradigms in British class analysis, summarising their rich accounts of cultural consumption; the second details how these might benefit from an appreciation of credit-debt and class struggle. The third section outlines the study methods used and data collection process. The fourth section marks this paper's empirical contribution by tracing the links between perceived inequalities and credit use amongst the participants. The fifth section discusses the links between inequality, credit and financial expropriation by credit issuers, after which a conclusion is presented.

\section{Emergent paradigms in British class analysis}

The concept of class has undergone various adaptations, but fundamentally is about the exploration and description of inequality (Tyler, 2015). Recent approaches to class analysis have developed a multi-dimensional conceptualisation of inequality, with Bourdieu's class scheme becoming central. Bourdieu $(1984 ; 1986)$ 's class theorisations are based on three distinct, but interconnected, forms of capital. Economic capital refers to wealth, savings, and income; social capital to the connections, networks, and organisational affiliations that people can draw on. Cultural capital is defined in more ambiguous terms. Bourdieu (1986) refers to three forms: institutionalised credentials; 
objective possessions that transmit taste; and embodied attributes, such as accent, demeanour and dress, that take time and resources to inculcate and assimilate.

Class analysis throughout the twentieth century mostly associated class with position and role in the production system, with occupation regarded as its central indicator (Rose, 2008). However, the notion of 'capital' opens the way to consider the consumption sphere in our understanding of class processes. Bourdieu (1984) outlines how property such as 'houses, furniture, paintings... cars... clothes' (p. 169), and the 'fields of stylistic possibility', such as 'holiday resorts' and 'design or furnishing of house or garden', provide 'inexhaustible possibilities for the pursuit of distinction' (p. 223) and the drawing of class boundaries. Consumption is viewed in 'dispositional terms, located within the pre-reflective, embodied nature of practical activity' (Bottero, 2010, p. 4). It is not merely a matter of what is being consumed, but the way it is consumed (Holt, 1998; Friedman et al., 2015). Thus, for Bourdieu, inequality is also reproduced through cultural preferences, distinctions that place individuals and construct 'classed identifications' (Bottero, 2004, p. 990).

The most extensive recent empirical explorations of Bourdieu's ideas in Britain were conducted by the Cultural Capital and Social Exclusion (CCSE) project (Bennett et al., 2009), and the Great British Class Survey (GBCS) project (Savage et al., 2013, 2015) (see Silva, 2015, for a critical discussion). The CCSE and GBCS sit within the 'capitals, assets and resources' (Savage et al., 2005) framework, which regards inequalities as cumulative. Savage (2015) outlines that, instead of viewing the advantages of one class as incumbent on the extraction of value from other classes, the GBCS explores how 'inequalities are produced by different kinds of capital accumulation' and how the 'advantaged classes secure their advantages' (p. 233, 234), which alters how class exploitation is perceived. Both projects develop quantitative models of class position based on measures of economic, cultural and social capital, moving beyond solely occupational-based classifications. Each project affirms Bourdieu (1984)'s view that those in higher class positions have higher volumes of capital and are more likely to engage in 'highbrow' activities (such as eating in French restaurants and attending opera). The attempts to measure patterns of 'legitimate' cultural taste, so verifying Bourdieu's theory, operationalise only a narrow understanding of his idea (Friedman et al., 2015), and may overlook the symbolic importance of mundane consumption in class differentiation (Flemmen, Jarness, \& Rosenlund, 2018).

Bennett et al. (2009, p. 169) do nonetheless explore embodied cultural capital, and find that through 'bodily practices' associated with eating and clothing, individuals 'display the insignia of unequal possessions of cultural capital': which marks their social position and contributes to 'schemes of social classification'. Thus the contest over cultural value is also rooted in the everyday, according to people's position in a larger system of cultural objects and practices that offer meaning (Friedman et al., 2015). Savage et al. (2015) touch on this, detailing how those with higher volumes of capital 
sometimes viewed the cultural practices they regarded as inferior as indicative of pathological identities, which they would meet with contempt. Others similarly draw attention to how the homes, bodies, and clothes of the working classes are deemed to signify some deeper pathology, which is 'ignorant, brutal... tasteless' (Lawler, 2008, p. 140), and 'disgusting' (Tyler, 2013, p. 23; Skeggs, 2004). Whereas those who have accumulated high volumes of economic capital are assumed to have done so through meritocratic achievement and hard work (Littler, 2013; Savage et al., 2015), those at the bottom of the income spectrum are blamed for their poverty and disadvantage (Bamfield \& Horton, 2009). This research provides further evidence that rhetoric explaining the causes of inequality has shifted from structural to individual factors (Crompton, 2010).

Savage et al. (2015) find 'signs of felt snobbery' among those with lower volumes of capital, who sometimes feel they are 'being looked down upon' (p. 385), and have a 'feeling of deficit' when comparing their circumstances to others (p. 208). These feelings are intensified when 'cross-class interaction' occurs, whereby an individual finds themselves 'in settings with people from different class backgrounds' (Savage et al., 2015, p. 378). These are important findings, because they suggest a potentially 'enhanced role of external appearance' - of objectified forms of cultural capital - in which the visual aspect of people, objects, and artefacts have become more significant (Friedman et al., 2015, p. 5). Regardless of the form that cultural capital takes, the CCSE and GBCS, like Bourdieu, view differences as predominantly stemming from primary socialisation and pre-reflective dispositions.

\section{Class struggle, reflexivity, and the role of credit in consumption}

Cultural class analysis provides a powerful picture of how class inequality is marked in daily life and perceived by individuals in different positions within the social structure. Yet it overlooks a body of research showing how people struggle against, deflect and resist 'discursive practices of othering' (Tyler, 2015, p. 501) and 'signs of felt snobbery' (Savage et al., 2015, p. 385), triggered by class inequality (Latimer \& Munro, 2015; Lawler, 2008; Skeggs, 2004; Tyler, 2013, 2015). These scholars recognise that class inequality creates anxiety, defensiveness and precarity at the heart of identity, but also reveal how people seek to repudiate the variety of threats induced by inequality and blame: for example, through disidentification (Bottero, 2004; Shildrick and MacDonald, 2013), engagement with forms of grading (Latimer and Munro, 2015), and resistance (Tyler, 2015). In cultural class analysis, little attention is paid to struggle and reflexivity, or forms of conscious action: especially via cultural consumption.

Moreover, the focus on measuring differences in cultural consumption has obscured the role of financial resources (specifically, credit) in facilitating consumption of an object or activity (Crompton, 2010; Skeggs, 2015). There is little by way of elaboration in cultural class analyses of 
the proliferation of credit-debt within Britain. This is surprising given Bourdieu's discussion of credit in his seminal text, Distinction. In a process he describes as the 'dialectic of downclassing and upclassing', Bourdieu (1984, p. 157) argues that all groups, regardless of the position they occupy, aspire 'to possess that which the group just ahead already have', and he outlines why 'it is no accident that credit is so important':

The imposition of legitimacy which occurs through the competitive struggle and is enhanced by the gentle violence of cultural missionary work tends to produce pretension, in the sense of a need which pre-exists the means of adequately satisfying... [I]n the long run, the only alternatives are credit, which allows immediate enjoyment of the promised goods but implies... 'imitation' - mock luxury cars, mock luxury holidays and so on. (p. 160)

Bourdieu recognises how credit is an additional resource that can be used by individuals to imitate the consumption of other classes in order to subvert schemes of classification. He also recognises how the 'competitive struggle' over 'legitimate' culture produces 'pretension'; in other words, affected behaviour, intended to give an appearance of greater importance and/or status than a social position commands, or would be permissible without access to credit. Indeed, without access to credit, spending is limited by financial resources generated from wages, investments and/or profits from capital investment, which mould patterns of consumption (Harris, Naylor, \& Seldon, 1961).

Nonetheless, according to Sullivan (2008, p. 52), proliferation of credit has made it possible for many 'people to simulate the consumption of a class to which they may not yet belong or to maintain the typical consumption of a class from which they do not wish to fall'. Despite the ready availability of credit, there have been only limited attempts to apply a Bourdieusian framework. In the US, Bernthal, Crockett, and Rose (2005) explore the connection between credit card practices, embodied cultural capital and consumption patterns: detailing how creditcard-fuelled consumption helps further distinguish the lifestyles of those with higher and lower forms of cultural capital. However, they do not address how experience of class inequality may influence credit use; nor Bourdieu's proposition that credit is used for 'imitation' and could be indicative of credit users' attempts to simulate the consumption of different classes (Sullivan, 2008). These lacunae form the essence of the empirical enquiry.

The position I adopt aligns with Tyler (2015, p. 507), who states that to grasp the problems wrought by inequality, class analysis should focus on 'exposing and critiquing the consequences of classificatory systems' and the values and judgements they establish; as well as detailing individuals 'struggles against the inequalities' that these classifications 'name and prescribe', along with the strategies they employ to ameliorate their effects. At this juncture, unsecured credit-debt provides a crucial avenue of investigation. In the analysis, I explore how unsecured credit influences the 'fields of stylistic possibility', such as holiday resorts and home renovation (Bourdieu, 1984, p. 223), 
consumption of cars and goods, and bodily practices associated with clothing and eating out. The analysis diverges by stressing how these practices are tied up with struggle and class positioning in response to perceived class inequalities.

\section{Methods}

To obtain a sample of individuals with experiences of using credit and managing problem debt, the debt charity StepChange were approached. Founded in 1993, StepChange is a free-to-customer provider of specialist problem debt advice and solutions in the UK. The financial circumstances of those who contact either a free-to-customer or fee-charging debt management service are similar; they often do so after defaulting on their credit agreement(s), so require acute financial advice. Indepth face-to-face interviews were carried out across Britain, with 21 individuals undertaking a debt management plan (DMP). A DMP is an informal debt solution between an individual and their creditor(s), arranged by a debt management service. Income and priority expenditure are determined before the monthly budget surplus is offered as a repayment to reduce, and eventually clear, total problem debt. Approximately 129,000 people are repaying problem debts through a StepChange DMP: around 32\% of the estimated 400,000 DMP users in Britain (Bailey, 2016). The findings drawn from the participants of this study thus have wider applicability.

The sample consists of nine women and 12 men, with ages ranging between 30 and 72 years, and a mean of 50.2. When participants contacted StepChange for help, their problem debt ranged from $£ 11,000$ to $£ 105,000$, with a mean of $£ 43,314$. At the time of interview, problem debt ranged from $£ 1,680$ to $£ 90,000$, with a mean of $£ 25,763$. On average, participants had cleared $£ 17,551$ each, although there were large variations between them.

Interviews were audio-recorded, lasted between one and three hours, and organised around a range of thematic headings: starting with participants' biographies, moving through their credit use, build-up of debt, default; and finally, their debt management. Interviews were transcribed verbatim and coded using ATLAS.ti. The codes were formed deductively and inductively: whereas examples of when participants used credit to acquire certain 'capitals' were coded, other codes emerged spontaneously. Participants have been given pseudonyms; with key dates, events and locations altered to protect their anonymity.

\section{Key findings}

\section{'Balancing out' living standards: credit and its use in overcoming feelings of deficit}

There are examples where participants access credit to enhance their specific stores of cultural capital; and do so in ways that seem driven by pre-reflective, embodied dispositions. Yet there are also examples of their utilising credit in a reflexive way, as they attempt to overcome perceived class 
inequalities. Two participants who renovated their homes with credit did so after divorce. Savage et al. (2015, p. 378) note that class positions are closely tied up with personal relationships, and divorce can act as a 'catalyst' for downward mobility and anxiety about one's 'place in the world'. However, credit can be used to mitigate feelings of deficit and downward mobility triggered by relationship breakdown. George, a 63-year-old retired psychiatric social worker, states he had 'nothing' after his divorce, so 'furnished and equipped' his new flat 'on credit'. Instead of being 'sensible' and buying goods within his means, he still wanted to 'live the same kind of lifestyle', because he did not want his children to 'see a father who was suffering or struggling'. Anne, a 50-year-old business mentor earning $£ 30,000$ a year, has similar experiences. Despite still being able to buy a three-bedroom semidetached house in a 'middle class area' after her divorce (albeit on a 25-year mortgage), Anne refracts this through the prism of her ex-husband's 'big executive four bedroom' house, causing her deep anxiety:

I think I wanted to make sure [my son] wasn't missing out through the marriage breaking down... I don't want to cry but I wanted him not to feel left out and love his mum really... I said to [my son] the other day I was having these nightmares about stuff... I said I had the feeling that I was a poor relative with dad now having lots of money and a big house... I think I tried to compensate for that [and] sort of balance out the standard of living.

To 'balance out' their unequal circumstances and mitigate feelings of being the 'poor relative', Anne drew upon various credit agreements to upgrade the kitchen, buy a sofa and soft furnishings; and more specifically, buy her son a log cabin for the garden, with a bed, TV and computer, so 'he had somewhere to go in the house'. Anne's reflexivity was stirred after she split from her partner; their respective home environments came to signify 'boundaries of class', generating a 'sense of discomfort' and 'heightened sense of self-awareness' (Savage et al., 2015, p. 381). Credit became a resource enabling her to soften this imbalance.

'Balancing out' of living standards is also apparent in some participants' social interactions when eating out with friends and family. According to Bennett et al. (2009, p. 169), although individuals share a generic involvement in eating out, there are 'significant differences in participation, knowledge and taste between social groups'. Eating out forms an activity that can signal someone's economic and cultural capital. Consequently, an inability to eat out, or eat at a specific type of restaurant, can play into an individual's self-perception. Credit can help overcome these feelings of deficit: as Karen, a 49-year-old holistic therapist earning $£ 25,000$ per year, poignantly reveals:

Karen: I don't want people to think I can't afford anything. It's that kind of thing that makes you think, well, I can buy that [with credit]. 
Interviewer: So you felt credit gave you a sense you could afford it?

Karen: $\quad$ You could afford it! Not to keep up with the Joneses or anything. Like when we went with [Pete and Brenda] to London we could eat in a very expensive restaurant. But they'd do it out of their bonuses and their salaries because they're both very well paid. We did it with a credit card or money from a loan. But I didn't want them to know that we couldn't necessarily afford to do that... It was just that we said we'd go and we wanted to sort of be equal... but you know, there's a price to pay.

Karen and her partner drew upon credit to increase their economic capital and eat in a 'very expensive restaurant', with the intention of obscuring their friends' judgement about their actual economic capital. This occurred because Karen was aware of her friends' superior class position. It was therefore more about the cost of the food than its 'highbrowness'. Karen's statement that 'you could afford it!' shows how credit is a resource which turns the abstract into the material. Furthermore, as the reference to being 'equal' reveals, in certain situations, credit permits individuals to bypass the effects of economic inequality in relational interactions. By simulating economic capital with credit, Karen and her partner distort synergies between economic position, cultural practices and symbolic cues, influencing how their friends and other people in the restaurant may classify them.

Even when economic and cultural capital differentiate individuals and social groups, we see in the above accounts how credit might nullify or lessen these distinctions. Nonetheless, in acknowledging 'there is a price to pay', Karen alludes to the potential consequences of using credit to fund consumption. In her case, it led to default and debt becoming 'all consuming'

\section{'I'm better than him': credit and struggles with schemes of classification}

Many participants articulate perceptions of schemes of classification linked to consumption: whereby homes, cars, clothes, holiday resorts, goods and possessions are used to place an individual's class position. Justin, a 34-year-old owner of a recruitment firm earning $£ 32,000$ per year, reflects: 'Things you pick define who you are... And if you are someone that's rich, you're defined by designer clothes, and if you're not so well off you can't afford those things'. Bennett et al. (2009) and Savage et al. (2015) recognise the importance of clothes in symbolising social position. Some participants have an intuitive sense that clothes can signify a visible form of class position, so attempt to curtail this. Anne, for example, utilised credit in shops to buy clothes that were 'more expensive', with 'nicer finishes'; but reflects, 'there's that keeping up element typifies how I am. Then you scratch the surface and you go, "bloody hell, she's got no money". Like all fur coat and no knickers expression'. Anne consumed clothes with credit to enhance her placement on 'schemes of social classification' (Bennett et al., 2009, p. 169), and is aware that this helped obscure her economic capital. 
Sean, a 38-year-old recruitment consultant earning $£ 25,000$ per year, provides a more specific example of how the acquisition of clothing is tied to struggles over schemes of classification, when discussing an interaction with a work colleague:

There's a lad at work, he's only a trainee, he's probably on $£ 19,000$, but he's got the latest. I got this [jacket] out of the catalogue for $£ 100$. I didn't need it but [he] had bought the latest Superdry jacket that are hundred something pounds, so I had to go and get one. I went into work with it and started to tell him about it and he just said he'd seen it in a shop for $£ 35$. And that upset me because I'm better than him. It's kind of weird. An argument took place. It annoyed me because he still thinks he's got the better jacket... And on the day when the jacket came I was as high as a kite. It's weird. I didn't need [the jacket]. I don't need half the things I've purchased.

Even though Sean acknowledges that he did not 'need' the jacket, he believes that others would classify his clothing to formulate an idea about his social position. As such, he used credit to buy the jacket, believing it proved he was 'better' than his work colleague. Yet its status was downgraded in Sean's mind because his colleague indicated it could be bought at a cheaper price: leaving him going from feeling as 'high as a kite' when the jacket arrived, to 'upset' and 'annoyed' that it did not convey the meaning intended.

That Sean feels the need to engage with a trainee colleague in a lower position, who earns less than him, reveals the precariousness of his mindset. It further suggests that credit induced consumption is driven by downwards and upwards comparisons (Bourdieu, 1984; Frank et al., 2010), and mundane consumption and goods are important in social differentiation. Indeed, this was not an isolated incident but reflects an underlying orientation, which explains how he has accumulated over $£ 26,000$ in unsecured debt. Ultimately, Sean is in tune with the things around him - what others have - and reflexively considers his own position in response to these external stimuli; and acts to overcome the anxiety it creates. At various times throughout the interview, Sean used the word 'latest' to describe his consumptive activity. In other words, obtaining innovated goods when they are disseminated defines his sense of self: 'I have to have the latest goods; I have to have higher value'. Providing an explanation for his behaviour, he reveals, 'I don't want to be seen as where I am at the minute. I want to be seen as someone successful because that's what I want to be and I will be'. Sean has translated his need to 'feel better' and desire to be 'seen as someone successful' into acquiring clothes and other goods, often with credit, to alter his external appearance (Bennett et al, 2009; Freidman et al., 2015), hoping this shifts how others classify him.

David, a 46-year-old heavy goods driver, who lives in a mortgaged property with his wife and two children, similarly indicates how credit enabled him to purchase the 'latest' goods and possessions. He offers an insightful perspective on these practices: 
I think [using credit] was basically almost like you could keep up with your friends, neighbours, people you knew. You'd see somebody get some flash thing and you'd think... if I don't get something nice I'm going to be classed as being not as well off as this person. I've got to get the new TV that's come out on the market just to prove that I am financially viable. It was hiding the truth that you didn't perhaps earn as much as some people. But as far as I knew they were probably all doing the same as me, using credit to buy nice goods. It was almost like a status symbol... It did feel good at the time... But it was false.

Bourdieu (1984, p. 160) notes how there may be 'symbolic' consequences for those who arrive late to 'an activity or asset'. David avoided this by using credit; he believed that obtaining the 'latest' assets 'on the market' allowed him to 'keep up' and to 'keep his distance' from others (Bourdieu, 1984, p. 157). Reading signals sent by others was difficult, because he could not determine whether they were acquired with income or credit. Yet he still took part in the 'race' to avoid being 'classed' as economically and culturally inferior, and project a social position of being 'financially viable'. As David alludes, those who are static while others accumulate capital may feel a sense of deficit and impending anxiety.

\section{Developing styles of life with credit and altering dispositions}

We see similar processes in participants' acquisition of cars. According to Stokes and Hallet (1992, p. 178), cars are perceived as a mobile 'status symbol' because of their 'ability to place people on a number of scales of social positioning'. Proliferation of credit has complicated this by enabling individuals to acquire hitherto unavailable cars; this has intensified in recent years (Inman, 2017). Anthony, a 49-year-old stock control manager earning $£ 29,000$ a year, explains how the acquisition of a better model car with credit directly influenced his self-perception in relation to others:

[Credit] opens up a completely different world to you; it allowed us to do things we had never been able to do in the past... [So] instead of having a beaten up Astra I turned up [to work] in a new Saab. And you don't feel as bloody useless as you used to. You know I used to park as far away as I could from anybody [at work] to avoid them seeing [the car] I was coming in with... [But] all of a sudden you'd turn up in nice clothes, you'd turn up in a nice car, and you'd get out at the supermarket next to somebody in a beaten up [car]... and you just feel so much better about yourself.

How Anthony perceives links between inequality and consumption permeates his account. He internalised 'scales of social positioning' associated with cars, and after purchasing one with credit, believed his placement had altered in relation to others. In other words, he engaged in a struggle with classifications and their grading; and through his credituse, he obtained assets which made his 'value' visible to others (Latimer \& Munro, 2015). 
The key here is how this altered positioning reconstructed his sense of self and self-worth in a positive way. Similarly, David, for whom it 'felt good at the time' to buy the 'latest goods', later elaborated: 'You thought you're part of the elite at the time. That's the only way to think about it'. That David, a heavy goods driver with a secondary education, felt part of the elite indicates credit's capacity to distort links between occupation, economic capital and lifestyle. An individual's creditfuelled consumption can give the impression of class mobility, even when their position in the productive sphere remains fixed. Indeed, many participants' narratives are littered with semantics such as 'worked up', 'progressing', 'self-development', and 'better myself' when describing their credit use. Credit permitted them to insert more everyday reflexivity into their lives: whether to balance out living standards or through struggles with classification.

Over time, these credit-fuelled practices can modify tastes and lifestyles - as John, a 51-yearold process technician earning $£ 33,000$ per year, details when outlining the influence of his $£ 81,000$ worth of unsecured credit:

John: $\quad$ I suppose the... one vice that I suddenly built myself was shopping, and I collected whisky, still do, bloody expensive. But you know it's nice to be able to do these things.

Interviewer: So what does shopping offer then?

John:

It's the ability to go into somewhere pick up what you want and know you can walk out with it. It's you know going on holiday to Scotland wandering into a distillery and saying 'I'll have that and that, thank you very much', and then stick it in the cupboard.

John acknowledges his credit use enabled him to overcome material constraints, leaving him able to 'go into somewhere, pick up what you want' and 'walk out with it', mirroring Bernthal et al. (2005)'s findings. An offshoot of John's use of credit to go on holiday was the development and refinement of a taste in 'whisky' - a 'unique, original' taste which helped foster an 'individualised subjectivity' (Holt, 1998, p. 14, 21). As credit is utilised to develop styles of life, it can inculcate forms of socialisation which alter individuals' perception of their social position.

The irony for John, David, and the other participants is these effects did not last. Their creditfuelled consumption resulted in the accumulation of large sums of unsecured debt and consequently, financial hardship.

\section{Discussion: Borrowed identities and changing class positioning}

The findings here correlate with Bennett et al. (2009, p. 169)'s assertion that consumption patterns 'contribute to the marking of social position and schemes of social classification'. The data further reveals how unsecured credit can be utilised to consume goods, accumulate possessions, and engage in activities to influence social position. The question, though, is whether unsecured credit 
really does help to build capital and improve someone's class positioning. Participants used unsecured credit over anything between four and 47 years, accumulating balances across multiple agreements. They increased their accumulation of objects and participation in cultural activities over time, symbolically transmitting their competence in acquiring objectively available resources (Bourdieu, 1986).

Although somewhat of an imitated competence, as Bourdieu (1984) theorised, my contention is these processes can enhance an individual's stores of capital, with enough potential to affect class position, for three main reasons. First, as participants' indicate, credit emancipates individuals from fixed income and fixed patterns of consumption (Harris et al., 1961), making it possible to maintain consumption of a class from which they do not wish to fall, or simulate consumption of a class to which they may not yet belong (Sullivan, 2008). Second, these credit practices can signal 'privileges and advantages' in users' 'social life' (Jarness, 2017, p. 361): which would not be possible if it were inaccessible. As Bourdieu (1984, p. 376) put it, conspicuous forms of consumption are often an 'excellent investment in social capital'. Third, because these practices can inculcate styles of life that alter self-perceptions and dispositions - this suggests that credit-debt is a transformative force (Montgomerie and Tepe-Belfrage, 2018). The capital-based approach to class - the crystallisation of inequalities and accumulation of advantages over time (Savage et al., 2015) - is thus influenced by the availability and use of credit as a resource. Furthermore, the examples of the restaurant (Karen) and the jacket (Sean) illustrate the symbolic importance of mundane consumption and goods in social differentiation. The links between capital - or resource - conversion and mundane forms of symbolic capital are important considerations for future research.

There is evidence suggesting that these mechanisms are rudimentary to contemporary forms of governance (Payne, 2013). Inequality, and the meritocratic and individualising discourses explaining its 'causes', are deployed to spur economic and cultural activity (Harris et al., 1961; North, 2005; Meadowcroft, 2008). The stress on 'making success and failure visible' is intended to destabilise and unsettle 'any certainties over class positions' (Latimer \& Munro, 2015, p. 428). The anxiety, defensiveness, and precarity at the heart of identity (Latimer \& Munro, 2015; Lawler, 2008) is thus linked to the instability, insecurity and visibility which class inequality creates. Participants noticeably internalised differences in economic capital, visibility of objects, and engagement in cultural activities of their friends, work colleagues, family members and acquaintances. They utilised credit to construct 'classed identifications' (Bottero, 2004, p. 990) to ameliorate feelings of deficit and anxiety, and advance their placement on schemes of classification in relation to others. Credit use, then, can reflect an individual's attempt to disidentify with their class position, mirroring patterns identified by other research (Bottero, 2004; Skeggs, 2004; Shildrick \& MacDonald, 2013; Tyler, 2013). These findings indicate that reflexivity can emerge at moments of disruption to social position 
and times of crisis (Bourdieu, 1990; Sweetman, 2003; Bottero, 2010) triggered by experiences of inequality; which influence consumptive practices to maintain (Montgomerie, 2009) or enhance (Frank et al., 2010; Bertrand and Morse, 2011; van Treeck, 2012) class position. That credit emerges as a resource at this juncture is not coincidental. As Poster (2013) found, financial institutions train employees to utilise types of emotional work when selling credit, principally through appealing to the individual's deep sensitivities about money, family and self.

However, there can be serious consequences of the promotion and use of creditfor the practices specified here, as high personal debt levels can increase risk of default should a change in circumstance occur. All participants encountered this: citing relationship breakdown, poor health, redundancy and reduced incomes as factors triggering default. Credit is produced as a 'profit-making enterprise' (Marron 2007, p. 104), with capital extracted from interest that costs the average family $£ 1,860$ per year (The Money Charity, 2017, p. 5), and penalties if default occurs. Each participant is now making sacrifices to repay their problem debt with current income, with DMP payments ranging from $£ 45$ to $£ 930$ per month, and repayment terms ranging from four to 43 years (with an average of 15). Ultimately, the class effects of their credit-fuelled consumption did not last in the long run, resulting instead in financial hardship and severely diminished stores of economic capital (Bernthal et al., 2005).

The imperative of the financial sector is to extract the maximum profit from their clients, which sometimes involves placing them close to and beyond their credit limits (Walker, Hanna, Cunningham, \& Ambrose, 2014). Participants' experiences are characterised by multiple forms of 'financial expropriation' by financial institutions (Lapavitsas, 2009, p. 131), highlighting how the economic advantages of those working in the financial sector are partly incumbent on the dispossession (Harvey, 2004) and extraction of value from other individuals (Skeggs, 2015). This is rooted in financial deregulation under the Thatcher government, undertaken in alliance with financial elites (Davies \& Walsh, 2017), which propelled proliferation of credit and sowed the seeds of the 2007-8 financial crisis (Sparkes et al., 2018).

Increasing inequality is a mechanism which supports advanced financialised economies. Individuals are provided with credit as a means to ameliorate anxiety and feelings of deficit; but find themselves entangled in complex liens of debt, which allow secondary forms of exploitation to occur (Soederberg, 2013). Thus I concur with Skeggs (2015), who argues: 'If we just understand advantage we lose sight of the historical process that brought inequality into effect' (p. 211); and of the groups who use it as 'a vehicle for legitimating the upward redistribution of wealth' (p. 219).

\section{Conclusion}


Amplifying inequality heightens an individual's awareness of the consumption, accumulation and display of different forms of capital by others. Bourdieusian-inspired cultural class analysis further captures how individuals in different positions within the social order perceive and experience differing volumes of capital and accumulating class inequalities. Participants' experiences of class inequality disrupted their social position; so they turned to credit to renovate property, consume goods, clothes and cars, and engage in cultural practices, ameliorating their feelings of deficit and anxiety and advancing their placement relative to others. Their accounts demonstrate how they have stood back from their cultural frames, reflected critically on their relative class position, and drawn upon credit to maintain or enhance this. These credit-acquired 'classed identifications' reflect an imitated, borrowed competence in acquiring objectively available resources, as Bourdieu theorises. Yet by using credit to acquire and accumulate otherwise inaccessible class identifiers, individuals do alter their symbolic representation in hierarchical schemes of social classification: blurring class boundaries, and altering their self-perceptions and dispositions. The findings further indicate the symbolic importance of mundane consumption and goods in social differentiation, and the role of resources in this process: important considerations for future investigation.

There is, finally, the question of whether the class insecurities and credit use embodied by this study's participants, a group of people of modest means, cut across the social pyramid. The discussion set out how the financial system is driven by an undergirding logic that credit-debt is available and promoted to individuals as an additional resource; while inequality and individualising discourses explaining its 'causes' spur economic and cultural activity. Participants' observations highlight the difficulty of discerning who is using credit, so it acts as a hidden tool in the acquisition and transmission of capital. Thus, the analysis does indicate that volumes of capital may be partly linked to scales of indebtedness: another possible area for future research.

Furthermore, these processes entangle individuals into complex liens of debt - which can lead to over-indebtedness, crisis, hardship, dispossession and financial expropriation. Accordingly, these findings help illustrate how investigating credit-debt, states of indebtedness, and financial capitalism more broadly, can better inform understandings of class inequality, exploitation and struggle.

\section{References}

Ando, A., \& Modigliani, F. (1963). The 'lifecycle' hypothesis of saving: Aggregate implications and tests. American Economic Review, 53, 55-84.

Bailey, A. (2016). The Rationale for the FCA's Mission. City Banquet Speech. Retreived from: https://www.fca.org.uk/news/speeches/rationale-fca-mission-context-operates.

Bamfield, L., \& Horton, T. (2009). Understanding Attitudes to Tackling Economic Inequality. Joseph Rowntree Foundation. Retreived from: https://www.jrf.org.uk/report/understandingattitudes-tackling-economic-inequality.

Bank of England. (2018). Money and Credit. Retreived From: 
https://www.bankofengland.co.uk/boeapps/database/index.asp?first=yes\&SectionRequired=A \&HideNums $=-1 \&$ ExtraInfo $=$ false $\&$ Travel $=$ NIxSTx

Bennett, T., Savage, M., Silva, E., Warde, A., Gayo-Cal, M., \& Wright, D. (2009). Culture, Class, Distinction. Oxon: Routledge.

Bernthal, M., Crockett, D., \& Rose, R. (2005). Credit cards as lifestyle facilitators. Journal of Consumer Research, 32, 130-145.

Bertrand, M., \& Morse, A. (2011). Consumption contagion: Does the consumption of the rich drive the consumption of the less rich? Retrieved from:

http://faculty.chicagobooth.edu/adair.morse/research/NBER reporter summaryAug2011.pdf

Bottero, W. (2004). Class identities and the identity of class. Sociology, 38, 985-1003.

Bottero, W. (2010). Intersubjectivity and Bourdieusian approaches to 'identity'. Cultural Sociology, 4, 3-22.

Bourdieu, P. (1984). Distinction. London: Routledge.

Bourdieu, P. (1986). The Forms of Capital. Marxist Internet Archive. Retreived from: https://www.marxists.org/reference/subject/philosophy/works/fr/bourdieu-forms-capital.htm.

Bourdieu, P. (1990). In Other Words: Essays Towards a Reflexive Sociology. Cambridge: Polity.

Crompton, R. (2010). Class and employment. Work, Employment \& Society, 24, 9-26.

Davies, A., \& Walsh, C. (2017). Distinguishing financialization from neoliberalism. Theory, Culture \& Society, 34, 27-51.

Duménil, G., \& Lévy, D. (2001). Costs and benefits of neoliberalism: A class analysis. Review of International Political Economy, 8, 578-607.

Flemmen, M., Jarness, V., \& Rosenlund, L. (2018). Social space and cultural class divisions: the forms of capital and contemporary lifestyle differentiation. The British Journal of Sociology, 69, 124-153.

Frank, R., Levine, A., \& Dijk, O. (2010). Expenditure cascades. Social Science Research Network. Retrieved from: http://ssrn.com/abstract $=1690612$

Friedman, S., Savage, M., Hanquinet, L., \& Miles, A. (2015). Cultural sociology and new forms of distinction. Poetics, 53, 1-8.

Froud, J., Sukhdev, J., Montgomerie, J., \& Williams, K. (2010). Escaping the tyranny of earned income? The failure of finance as social innovation. New Political Economy, 15, 147-164.

Goldthorpe, J. (1987). Social Mobility and Class Structure in Modern Britain. Oxford: Clarendon Press.

Harari, D. (2017). Household Debt: Statistics and Impact on the Economy. House of Commons Briefing Paper, Number 7584.

Harari, D. (2018). Household Debt: Statistics and Impact on the Economy. House of Commons Briefing Paper, Number 7584.

Harris, R., Naylor, M., \& Seldon, A. (1961). Hire Purchase in a Free Society. London: Institute of Economic Affairs.

Harvey, D. (2004). The 'new' imperialism: accumulation by dispossession. Socialist Register, 40, 63-87.

Harvey, D. (2007). A Brief History of Neoliberalism. Oxford: Oxford University Press.

Holt, D. (1998). Does cultural capital structure American consumption? Journal of Consumer Research, 25, 1-25.

Inman, P. (2017). Drive Carefully - I Can See a Credit Car Crash up Ahead. The Guardian, 8 May, 2017.

Jarness, V. (2017). Cultural vs economic capital: Symbolic boundaries within the middle class. Sociology, 51, 357-373.

Langley, P. (2008). The Everyday Life of Global Finance: Saving and Borrowing in AngloAmerica. Oxford: Oxford University Press.

Lapavitsas, C. (2009). Financialised capitalism: Crisis and financial expropriation. Historical Materialism, 17, 114-148.

Latimer, J., \& Munro, R. (2015). Uprooting class? Culture, world-making and reform. The 
Sociological Review, 63, 415-432.

Lawler, S. (2008). Identity: Sociological Perspectives. Cambridge: Polity Press.

Lazzarato, M. (2012). The Making of the Indebted Man: An Essay on the Neoliberal Condition. Los Angeles: Semiotext.

Littler, J. (2013). Meritocracy as plutocracy: The marketising of 'equality' under neoliberalism. New Formations, 80, 52-72.

Marron, D. (2007). 'Lending by numbers': Credit scoring and the constitution of risk within American consumer credit. Economy and Society, 36, 103-133.

Meadowcroft, J. (2008). Fight poverty, support inequality. Economic Affairs, 25, 58.

Montgomerie, J. (2009). The pursuit of (past) happiness? Middle-class indebtedness and American financialisation. New Political Economy, 14, 1-24.

Montgomerie, J. (2016). Austerity and the household: the politics of economic storytelling. British Politics, 11, 418-437.

Montgomerie, J., \& Tepe-Belfrage, D. (2018). Spaces of Debt Resistance and the contemporary politics of financialised capitalism. Geoforum.

North, R. (2005). Rich is beautiful: A Very Personal Defence of Mass Affluence. London: IEA Social Policy Unit.

Payne, C. (2013). The Consumer, Credit and Neoliberalism. London: Routledge.

Poster, W. (2013). Hidden sides of the credit economy: Emotions, outsourcing, and Indian call centres. International Journal of Comparative Sociology, 54, 205-227.

Rose, D. (2008). Socio-economic classifications: Classes and scales, measurement and theories. ISER, University of Essex. Retrieved from: http://www.iser.essex.ac.uk/files/esec/presentations_and_publications/Measurement_Socstrat. doc).

Savage, M. (2015). Introduction to elites: From the 'problematic of the proletariat' to a class analysis of 'wealth elites'. The Sociological Review, 63, 223-239.

Savage, M., Cunningham, N., Devine, F., Friedman, S., Laurison, D., McKenzie, L., ...Wakeling, P. (2015). Social Class in the 21st Century. UK: Pelican Books.

Savage, M., Devine, F., Cunningham, N., Taylor, M., Li, Y., Hjellbrekke, J., ...Miles, A. (2013). A new model of social class? Findings from the BBC's Great British Class Survey experiment. Sociology, 47, 219-250.

Savage, M., Warde, A., \& Devine, F. (2005). Capitals, assets, and resources: Some critical issues. The British Journal of Sociology, 56, 31-47.

Shildrick, T., \& MacDonald, R. (2013). Poverty talk: How people experiencing poverty deny their poverty and why they blame 'the poor'. The Sociological Review, 61, 285-303.

Silva, E. (2015). Class in contemporary Britain: Comparing the Cultural Capital and Social Exclusion (CCSE) project and the Great British Class Survey (GBCS). The Sociological Review, 63, 373-392.

Skeggs, B. (2004). Class, Self, Culture. London: Routledge.

Skeggs, B. (2015). Introduction: Stratification or exploitation, domination, dispossession and devaluation. The Sociological Review, 63, 205-222.

Soederberg, S. (2013). The US debtfare state and the credit card industry: Forging spaces of dispossession. Antipode, 45, 493-512.

Sparkes, M., Gumy, J., \& Burchell, B. (2018). Debt: Beyond Homo Economicus. In A. Lewis (Ed.), Cambridge Handbook of Psychology and Economic Behaviour (Second Edition) (pp. 198233). Cambridge: Cambridge University Press.

Stokes, G., \& Hallet, S. (1992). The role of advertising and the car. Transport Reviews, 12, 171183.

Sullivan, T. (2008). Debt and the Simulation of Social Class. In R. Brubaker, R. Lawless, \& C. Tabb (Eds.), A Debtor World: Interdisciplinary Perspectives on Debt (pp. 36-59). Oxford: Oxford University Press.

Sweetman, P. (2003). Twenty-first century dis-ease? Habitual reflexivity or the reflexive habitus. 
The Sociological Review, 51, 528-549.

The Money Charity. (2017). The Money Statistics 2017. Retreived from:

http://themoneycharity.org.uk/media/June-2017-Money-Statistics.pdf.

Toscano, A., \& Woodcock, J. (2015). Spectres of Marxism: A comment on Mike Savage's market model of class difference. The Sociological Review, 63, 512-523.

Tyler, I. (2013). Revolting Subjects: Social Abjection and Resistance in Neoliberal Britain. London: Zed Books.

Tyler, I. (2015). Classificatory struggles: Class, culture and inequality in neoliberal times. The Sociological Review, 63, 493-511.

Walker, C. (2011). "Responsibilizing" a healthy Britain: personal debt, employment, and welfare. International Journal of Health Services, 41, 525-538.

Walker, C., Hanna, P., Cunningham, L., \& Ambrose, P. (2014). 'A kind of mental warfare': An economy of affect in the UK debt collection industry. The Australian Community Psychologist, 26, 54-67.

Wood, J. (2017). The integrating role of private homeownership and mortgage credit in British neoliberalism. Housing Studies.

van Treeck, T. (2012). Did inequality cause the U.S. financial crisis? Macroeconomic Policy Institute (IMK), Düsseldorf. Retrieved from:

http://www.boeckler.de/pdf/p_imk_wp_91_2012.pdf 